\title{
Silencing/Voicing Transgender People at Work: An Organizational Perspective
}

\author{
DAVIDE BIZJAK
}

davide.bizjak@unina.it

University of Naples Federico II

\begin{abstract}
Narratives are a means of voicing in organizations. What it follows is a short reflection concerning the challenge taken by narratives of being the lens through which hearing voice from transgender people in organizations. This paper is aimed to scrutinize in what extent the role of transgender people narratives aids inclusion in organizations, through an organizational account of the underlying meanings in writing organizational stories. The reflection is mainly based on two concepts: the first one is silence, as a way to hide themselves in the workplace, and the second one is identity, as an apparatus of comparison between individual and organizational subjectivity. In this reflection, transgender people played the role of being a source of knowledge, triggering a debate concerning voice and silence in organizations.
\end{abstract}

\section{Introduction}

This contribution is aimed at providing a preliminary framework to investigate to what extent the role of transgender narratives aids inclusion in organizations. Inclusion is the primary purpose of Diversity Management (DM), broadly meant as the practice of knowing sources of difference among people in organizations. DM has increasingly become paramount for scholars due to many reasons. Globalization, for instance, requires more "interaction among people from diverse culture, beliefs, and background than ever before" (Senichev, 2013: 337 ), and the demographic change in society is also reflected in organizations (Gotsis and Kortezi, 2013).

From a theoretical point of view, the inclusiveness of Diversity Management can be analyzed with a particular focus on transgender people as an instance of a minority population in organizations. Since Davis (2009) pointed out that "transgender issues in the workplace represent the bleeding edge of the cutting edge in the LGBT (lesbian, gay, bisexual, and transgender) diversity human rights movement" (Davis, 2009: 109), meaning that they are subtly discriminated in and outside the policies adopted for LGBT+ individuals, they represent an extreme sample of the whole population that challenges the consolidated binary view of gender.

Therefore, discrimination in organizations does not only occur through visible and acknowledgeable practices (Barry, 1994), although they are accountable for lack of inclusion and for an increase of 'existence' of the binary system. The inclusion of minority groups, or of individuals belonging to minority groups, is also related to the majority group's perception of the advantages stemming from the introduction of inclusive practices. Indeed, if the majority group feels like they have something to lose from diversity, they will resist it (Ashikali and 
Groeneveld, 2015). The otherness related to minorities has a paramount relevance in inclusive processes; their perception of goodness or badness of inclusion will be reflected on the inclusiveness of the whole organization, possibly producing exclusion (Solebello et al., 2016).

Stories give the possibility of inclusion because they represent an expression of voice in organizations. Writing stories about their own account portray an individual point of view that allow the readers to dialogue with otherness. Transgender people writing stories of themselves engage a process of identity construction through corporeality (Phibbs, 2008) and organizational experience (Gherardi et al., 2018). Here I advocate a more performative approach to narrative research (Riach et al., 2016), meaning that narrative is not solely a method of social inquiry, but something capable of constructing identity in the organization (Dawson and Hjorth, 2011; Gartner, 2007). Reflecting on stories as a source of knowledge, more than empirical data, this contribution is organized as follows: in Section 2, a brief examination on how the binary view of gender makes organizations less inclusive is provided. In Section 3 , the concept of silence in organizations presented before the one of identity (Section 4) is explored. In the present reasoning, voicing transgender people in organizations through the use of narratives fosters an interaction concerning the identity, individual and organizational one. The modalities in which this latter occurs are addressed in the last part of this reflection, together with the conclusions.

\section{The binary view of gender in organizations}

For transgender people, performing their identity (Butler, 1999) means, on the one hand, challenging and defying the binary view of gender; on the other, seeking forms of acceptance and identification. The way transgender individuals 'live' the organization entails two aspects only apparently contradictory. Firstly, there is the challenge to gender binarism, which is not concealed by the identity cultivated by the hegemonic culture. Conversely, there is the need to be recognized as a member of the opposite sex, despite their own identity being different from both of the two most known gender. In other words, "the narratives of trans people who both embrace and challenge gender norms indicate the fragility of rigid dichotomous thinking with respect to 'nature' and 'culture', sex and gender" (Sanger, 2010: 270). Moreover, as Gagné and Tewksbury (1998) maintain, resistance and the willingness to adhere to the gender binary system are two faces of the same coin. Even individuals whose gender identities do not fit within the gender-binarism system have understood well the dominant belief system, for it is against that system that they react (Gagné et al., 1997). Despite the institutionalized nature of gender, its enactment has been analyzed from a Foucauldian perspective as a cultural statement (Townley, 1993). Following this tradition, the ways in which transgender individuals both are in opposition and conform to normative gender through their enactments of alternative gender identities have been analyzed. Acts or non-acts of opposition are often induced by the fear of discrimination and lack of acceptance and inclusion (Schwabenland and Tomlinson, 2015). This is the reason why the practice of silence is considered one of the most used practices in resisting to organization (Ward and Winstanley, 2003; Bell et al., 2011). Silence can be used not to increase or affirm new binary gender practices or to hide transgender people's own identity: it is also a way not to contribute to the construction of organizational identity, to keep separate the organizational identity from the individual one (Bizjak, 2018). Although these issues push individuals toward conflicting ends of a binary system, the commonality is that these are all pressures to stay within the binary system itself. Transitions 
from one gender to the other challenge the assumption that gender is a natural outgrowth of sex, to "the extent that gender rebels can be pressured to perfect their presentations of alternative gender to more closely approximate the 'opposite' sex" (Gagné and Tewksbury, 1998: 86-87). In this way, "the binary system is preserved, with those known as transgendered relegated to the third gender category of 'unnatural' or deviant" (Gagné and Tewksbury, 1998: 87).

Transgender individuals can teach a valuable lesson to the power dynamics of gender, as well as the possibility of resistance to the binary gender system's encroachment into the consciousness and identity of social actors. The performativity of their gender is an act of opposition to resistance aimed at negotiating their identity with the organizational one (Riach et al., 2014). Although many transgender people conform to binary expectations, according to which, for instance, feminine individuals will be female by actively transitioning, therefore, from one gender to the other, work and organizational context constitute essential settings for sexual minorities, through which they feel able to actively negotiate their terms of existence (Sanger, 2010), creating an opportunity to define their sense of self. Conversely, even resistance could lead to acts of discrimination, intimidation, and violence (Thomas and Plaut, 2008). Sometimes, the actual actors who resist are not conscious at all of their acts of resistance but that action is explicit and acknowledgeable by other members of the organization (Hollander and Einwohner, 2004), although we should consider the fact that "reciprocity and the idea of taking the other into account reflect masculine discourses of separation between self and others - a separation that can only be bridged by the recognition and attempted fulfilment of each other's (instrumental) self-interest" (Knights, 2015: 208).

\section{Voice/silence in organizations}

The silenced attitude of LGBT people in organizations contributes to perceive them as absent, so facilitating the lack of sexual orientation and gender identity in the agenda of diversity in organizations (Ward and Winstanley, 2003), despite the significant amount of literature on gay, lesbian and queer theory. Therefore, analyzing the role of transgender people concerning the silencing/voicing process is considered of paramount importance for this research. Furthermore, language is one of the factors that influence people in remaining silent (Ward and Winstaley, 2003). "Foucault is recognizing that discourse may be made up of silence and of things that do remain unsaid may be, in some way, forbidden. Silence, can therefore be illustrative of power being articulated, or as a means of resistance" (Ward and Winstanley, 2003: 1260). This section aims to understand how the categories of voice and silence impact on pathways of inclusion/exclusion. Silence and voice can be considered as two opposites categories, but sometimes silence can be interpreted as something different from the lack of voice (Van Dyne and Botero, 2003). The category of voice, on the one hand, is usually identified as a process to contribute either to the strategy or some practice considered too bad to keep the silence. Silence, on the contrary, is often seen by the LGBT community as a way to hide themselves from the other members of the organization and to avoid any performance about their sexual orientation or gender identity; i.e., organizational silence occurs when individuals choose to withhold their opinions about organizational problems (Morrison and Milliken, 2000). Even in the research field, the instance for inclusion and disclosure of sexual orientation are considered as "voice lesser heard in organization" (Ward and Winstanley, 2005). Lack of voice is usually attributed to lack of power (Morrison and Milliken, 2000), and for stigmatized 
groups, silence is considered to be either quiescent (voluntarily withholding of voice to protect oneself) or acquiescent (involuntary withholding of voice) that reflects an acceptance of adverse circumstances as being normal (Pinder and Harlos, 2001).

We can identify at least three types of silence linked to sexual orientation and gender identity in organizations:

- $\quad$ silence as covering the own sexual orientation and gender identity;

- $\quad$ silence as the transparency of heteronormativity, that it is always taken for granted;

- $\quad$ silence as the lack of acknowledgment by colleagues when the sexual orientation becomes overt.

These categories of voice and silence have been fruitfully scrutinized in organization studies to deal with the gender issue in organizations (for a literature review about this issue see Simpson and Lewis, 2005). What is still missing is the consideration of a poststructuralist view (Reingardè, 2010) of the performativity of gender identity and sexual orientation (Butler, 1999), instead of a binary view of gender.

According to Reingarde (2010), our knowledge about the experiences of silence or coming out at work and the influence of these experiences on their identity is still scarce, indeed, members of traditionally disadvantaged groups frequently experience discrimination in different forms that influence their silencing/voicing behavior, concerning the expression of dissenting views and their power to effect change (Bowen and Blackmon, 2003; Roberson and Stevens, 2006). As Allen (1995) noted, a high level of authentic voice in an organization is an indicator of successful diversity management. The next section is aimed to explain methodologically how to explore silence and voice processing in managing diversity in organizations.

\section{Identity in organizations}

The concept of organizational identity is widely debated in organizational literature and, more generally, in management studies, up to the point where organizational identity is linked almost to everything (Van Tonder and Lessing, 2003; Alvesson et al., 2008). Until the 1970s, in the field of sexual minorities in organizations, the word 'identity' was inexistent. As Anteby and Anderson (2014) underline, it was not until the 1980s that researchers in organizational contexts considered the concept of identity worthy of scholarly attention. The literature in the 1980s represents the matching between sexual minorities' identities and organizational identity, as "theories and research suggest that members' identities and organisational identity are closely linked" (Scott and Lane, 2000: 43).

From the extensive literature available on this topic, only those contributions that allow us to foster interaction between identity, at the organizational level, and the construction of identity, at the individual level, are considered relevant. Following this criterion, the concept of identity evolves, in organizational studies, from an individualistic (Albert and Whetten, 1985; Fiol and Huff, 1992; Brown and Starkey, 2000; Gioia et al., 2000) to a social view (Ashforth and Mael, 1989; Scott and Lane, 2000; Alvesson and Willmott, 2002; Alvesson et al., 2008; Hatch and Cunliffe, 2013). In this paper, they are investigated as two steps in the evolution of the concept of identity that can be subsumed under two broad categories: the permanence of those elements strictly linked to the organizational identity, and the construction of its own social 
identity, where elements of the individual identity interact with the organization, and vice versa. The two categorizations have been referred to as the classical and constructivist approach.

Albert and Whetten (1985) can be considered the pioneers of the classical approach. They were the first scholars to use the term 'organizational identity' in order to identify those elements that remain stable, substantial, and distinctive over the time. The concept of identity argued by Albert and Whetten (1985) is quite close to the etymology of the word 'identity': 'id' in Latin means 'the same', enduring over the time. The authors analyzed a period of economic crisis in their university, interviewing some of their colleagues and asking them what they would do and what their future plans would be in case they were fired. Their answers shed light on how the concept of identity crisis moves from individuals to organizations (Hatch and Cunliffe, 2013). From this point of view, the organizational identity becomes more visible and acknowledgeable during periods of crisis, in that precise moment when people are forced to question which elements are stable and which are not.

Gioia et al. (2000) expand on Albert and Whetten's (1985) elements of stability and distinctiveness over the time in organizational identity by adding that, while an organization might not be considered stable over time, it nevertheless preserves some of its features, thus, conveying a certain halo of stability. Thus, according to Gioia et al. (2000), what changes are the meanings associated with those labels that represent the stable elements of the organizational identity. In other words, while individuals perceive organizations as stable, they are always at the mercy of change as the meanings associated with those labels change. Gioia et al. (2000) call this process "adaptive instability" (Gioia et al., 2000: 63), which allows organizations' members to interpret specific organizational labels, in order to increase their self-esteem (Brown and Starkey, 2000).

Corley and Harrison (2009) state that organizations need to change to preserve their own identity. Therefore, identity is not only an individual issue but a collective one. Hence, it is strictly correlated with the interaction among individuals and the interaction between individuals and the organization in the broader social context. Likewise, the organization's identity is of significance for all the individuals belonging to that organization and, correspondingly, individuals' identity is of paramount significance for the organization. Thus, people who are undergoing a process of identity (gender) transition or those who are planning to do so should be valued by managers and by all the organization's members.

In the case of transgender people, individual identities are constantly, if not at the same time, resorting to different ways of displaying and hiding themselves (Ward and Winstanley, 2007), since their social identity is not correctly recognized by others (McLemore, 2015). While the non-recognition of a given social identity may be psychologically disruptive (McLemore, 2015), when an individual's gender identity is accepted, a strong feeling of inclusion is engendered (Rundall and Vecchietti, 2010). Transgender people construct their identity in the workplace because there is a dialectical relationship between social identity (also shaped by the organization) and the occupation (Beagan et al., 2012).

The constructivist approach assumes that the social context is a lever for the shaping of identity. Indeed, the Social Identity Theory (Ashforth and Mael, 1989) argues that the individual tries to obtain a better social identity thanks to the feeling of belongingness to groups that are highly considered and valued. Organizations' members face a social identification process through the organizational identity. Even for protected categories of 
workers, gender binarism lies behind the corner. Thus, even transgender and gender nonconforming people need to categorize themselves (Rundall and Vecchietti, 2010). Drawing on the social constructivist view of organizational identity means to admit that organizations do not remain stable over the time but, rather, they construct themselves every day, shedding light on the more evident phenomenon of whether the recognition of the individuals' identities matters for the whole organization as much as it matters for the individuals themselves. According to Knights (2015), it is possible to go beyond the subjectivity, looking at knowledge that derives from the individuals' representation. This representation is not limited to the categories imposed by society, but he argues for a dynamic ontology of the subject, aiming at dissolving, and not only challenging, the binary system of gender. While most people support biological determinism, we should question whether or not biology actually determines gender identity and if it is possible to change one's sex and assume a new identity (Dentice and Dietert, 2015).

\section{Final reflections and directions forward}

Traditionally, the literature dealing with transgender individuals in organization and the way they deal with binarism has paid attention to the perception of identity. As aforementioned, practices of silence have also been quite investigated in the literature, with a particular focus on acts of resistance to these practices (Riach et al., 2014; Ward and Winstanley, 2003).

Personal narratives permit oppressed people to affirm their subjectivities. The constitution of the subject through the act of writing is more suitable to a performative narrative analysis (Riach et al., 2016) as stories permit identifying rules and social interpretations of acts breaching and violating the rules. Narrative accounts, therefore, may provide examples of attempts to change or overcome the binary system. Therefore, stories enact voices in organizations, that is a way not to hide itself but conversely, construct a social reality where affirmative traits interact with a collectivity. Here comes up a measurable extent of inclusion, seen in the previous reasoning as the interaction between individual and organizational identity. Identity meant as putting together both stable and constructing elements, as a dialectic process in which not only the belongingness is realized, but even the uniqueness.

\section{Keywords}

identity; silence; narratives; inclusion

\section{Reference list}

Albert, S., Whetten, D.A. (1985) "Organizational Identity", In Research in Organizational Behavior (Vol. 7), L.L. Cummings and B.M. Staw (eds), pp. 263-295, Greenwich, CT: JAI Press.

Allen, K.R. (1995) “Opening the Classroom Closet: Sexual Orientation and Self-Disclosure”, Family Relations, 44 (2): 136-141. DOI:10.2307/584799.

Alvesson, M., Willmott, H. (2002) “Identity Regulation as Organizational Control: Producing the Appropriate Individual”, Journal of Management Studies, 39 (5): 619-644. 
Alvesson, M., Ashcraft, K.L., Thomas, R. (2008) "Identity Matters: Reflections on the Construction of Identity Scholarship in Organization Studies", Organization, 15 (1): 5-28.

Anteby, M., Anderson, C. (2014) “The Shifting Landscape of LGBT Organizational Research", Research in Organizational Behavior, 34: 3-25.

Ashforth, B.E., Mael, F. (1989) "Social Identity Theory and the Organization", Academy of Management Review, 14 (1): 20-39.

Ashikali, T., Groeneveld, S. (2015) “Diversity Management in Public Organizations and its Effect on Employees' Affective Commitment: The Role of Transformational Leadership and the Inclusiveness of the Organizational Culture", Review of Public Personnel Administration, 35 (2): 146-168.

Barry, D. (1994) "Making the Invisible Visible: Using Analogically-Based Methods to Surface Unconscious Organizational Processes", Organization Development Journal, 12 (4): 37-48.

Beagan, B.L., De Souza, L., Godbout, C., Hamilton, L., MacLeod, J., Paynter, E. and Tobin, A. (2012) “This Is the Biggest Thing You'll Ever Do in Your Life: Exploring the Occupations of Transgendered People", Journal of Occupational Science, 19 (3): 226-240.

Bell, M.P., Özbilgin, M.F., Beauregard, T.A. and Sürgevil, O. (2011) “Voice, Silence, and Diversity in $21^{\text {st }}$ Century Organizations: Strategies for Inclusion of Gay, Lesbian, Bisexual, and Transgender Employees", Human Resource Management, 50 (1): 131-146.

Bizjak, D. (2018) Diversity Management and Identity in Organisations: From Liminality to Inclusion, Newcastle upon Tyne: Cambridge Scholars Publishing.

Bowen, F., Blackmon, K. (2003) "Spirals of Silence: The Dynamic Effects of Diversity on Organizational Voice", Journal of Management Studies, 40 (6): 1393-1417.

Brown, A.D., Starkey, K. (2000) “Organizational Identity and Learning: A Psychodynamic Perspective", Academy of Management Review, 25 (1): 102-120.

Butler, J. (1999 [1990]) Gender Trouble: Feminism and the Subversion of Identity, New York, NY: Routledge.

Corley, K.G., Harrison, S.H. (2009) “Generative Organizational Identity Change: Approaching Organizational Authenticity as a Process", In Exploring Positive Identities and Organizations: Building a Theoretical and Research Foundation, L.M. Roberts and J.E. Dutton (eds), pp. 361-384, London: Routledge.

Davis, D. (2009) “Transgender Issues in the Workplace: HRD's Newest Challenge/Opportunity", Advances in Developing Human Resources, 11 (1): 109-120.

Dawson, A., Hjorth, D. (2012) "Advancing Family Business Research through Narrative Analysis", Family Business Review, 25 (3): 339-355.

Dentice, D., Dietert, M. (2015) "Liminal Spaces and the Transgender Experience", Theory in Action, 8 (2): 69-96.

Fiol, C.M., Huff, A.S. (1992) “Maps for Managers: Where Are We? Where Do We Go from Here?", Journal of Management Studies, 29 (3): 267-285.

Gagné, P., Tewksbury, R. (1998) “Conformity Pressures and Gender Resistance among Transgendered Individuals", Social Problems, 45 (1): 81-101. 
Gagné, P., Tewksbury, R., McGaughey, D. (1997) “Coming out and Crossing over: Identity Formation and Proclamation in a Transgender Community", Gender E Society, 11 (4): 478-508.

Gartner, W.B. (2007) “Entrepreneurial Narrative and a Science of the Imagination”, Journal of Business Venturing, 22 (5): 613-627.

Gherardi, S., Cozza, M., Poggio, B. (2018) “Organizational Members as Storywriters: On Organizing Practices of Reflexivity", The Learning Organization, 25 (1): 51-62.

Gioia, D.A., Schultz, M., Corley, K.G. (2000) “Organizational Identity, Image, and Adaptive Instability", Academy of Management Review, 25 (1): 63-81.

Gotsis, G., Kortezi, Z. (2013) “Ethical Paradigms as Potential Foundations of Diversity Management Initiatives in Business Organizations", Journal of Organizational Change Management, 26 (6): 948-976.

Hatch, M.J., Cunliffe, A.L. (2013) Organization Theory: Modern, Symbolic and Postmodern Perspective ( $3^{\text {rd }}$ edn.), Oxford: Oxford University Press.

Hollander, J.A., Einwohner, R.L. (2004), “Conceptualizing Resistance”, Sociological Forum, 19 (4): 533-554.

Knights, D. (2015) “Binaries Need to Shatter or Bodies to Matter: Do Disembodied Masculinities Undermine Organizational Ethics?", Organization, 22 (2): 200-216.

McLemore, K.A. (2015), “Experiences with Misgendering: Identity Misclassification of Transgender Spectrum Individuals", Self and Identity, 14 (1): 51-74.

Morrison, E.W., Milliken, F.J. (2000) “Organizational Silence: A Barrier to Change and Development in a Pluralistic World", Academy of Management Review, 25 (4): 706-725.

Phibbs, S. (2008) "Four Dimensions of Narrativity: Towards a Narrative Analysis of Gender Identity That Is Simultaneously Personal, Local and Global", New Zealand Sociology, 23 (2): 47-60.

Pinder, C., Harlos, H. (2001) "Employee Silence: Quiescence and Acquiescence as Responses to Perceived Injustice", Research in Personnel and Human Resource Management, 20: 33169.

Reingardè, J. (2010) "Heteronormativity and Silenced Sexualities at Work", Kultūra ir Visuomené: Socialiniu Tyrimu Žurnalas, 1 (1): 83-96.

Riach, K., Rumens, N., Tyler, M. (2014) “Un/Doing Chrononormativity: Negotiating Ageing, Gender and Sexuality in Organizational Life", Organization Studies, 35 (11): 1677-1698.

Riach, K., Rumens, N., Tyler, M. (2016) “Towards a Butlerian Methodology: Undoing Organizational Performativity through Anti-Narrative Research", Human Relations, 69 (11): 2069-2089.

Roberson, Q.M., Stevens, C.K. (2006) “Making Sense of Diversity in the Workplace: Organizational Justice and Language Abstraction in Employees' Accounts of DiversityRelated Incidents", Journal of Applied Psychology, 91 (2): 379-391.

Rundall, E., Vecchietti, V. (2010) “(In)Visibility in the Workplace: The Experience of TransEmployees in the UK", In Transgender Identities: Towards a Social Analysis of Gender Diversity, S. Hines and T. Sanger (eds), pp. 127-150, New York/London: Routledge. 
punt(Oorg

Sanger, T. (2010) "Beyond Gender and Sexuality Binaries in Sociological Theory: The Case for Transgender Inclusion", In Transgender Identities: Towards a Social Analysis of Gender Diversity, S. Hines and T. Sanger (eds), pp. 259-276, New York/London: Routledge.

Schwabenland, C., Tomlinson, F. (2015) "Shadows and Light: Diversity Management as Phantasmagoria", Human Relations, 68 (12): 1913-1936.

Scott, S.G., Lane, V.R. (2000) "A Stakeholder Approach to Organizational Identity", Academy of Management Review, 25 (1): 43-62.

Senichev, V. (2013) "Human Resource Diversity and Performance within the Frame of Organizations, Teams and Individuals", Business: Theory and Practice/Verslas: Teorija ir Praktika, 14 (4): 337-345.

Simpson, R., Lewis, P. (2005) "An Investigation of Silence and a Scrutiny of Transparency: ReExamining Gender in Organization Literature through the Concepts of Voice and Visibility", Human Relations, 58 (10): 1253-1275.

Solebello, N., Tschirhart, M., Leiter, J. (2016) "The Paradox of Inclusion and Exclusion in Membership Associations", Human Relations, 69 (2): 439-460.

Thomas, K.M., Plaut, V.C. (2008) "The Many Faces of Diversity Resistance in the Workplace”, In Diversity Resistance in Organizations, K.M. Thomas (ed.), pp. 1-22, New York/London: Lawrence Erlbaum Associates.

Townley, B. (1993) "Foucault, Power/Knowledge, and its Relevance for Human Resource Management", Academy of Management Review, 18 (3): 518-545.

van Dyne, L.A.S., Botero, I.C. (2003) “Conceptualizing Employee Silence and Employee Voice as Multidimensional Constructs", Journal of Management Studies, 40 (6): 1359-1392. DOI:10.1111/1467-6486.00384.

van Tonder, C.L., Lessing, B.C. (2003) “From Identity to Organisation Identity: The Evolution of a Concept", SA Journal of Industrial Psychology, 29 (2): 20-28.

Ward, J., Winstanley, D. (2003), “The Absent Presence: Negative Space within Discourse and the Construction of Minority Sexual Identity in the Workplace", Human Relations, 56 (10): $1255-1280$.

Ward, J., Winstanley, D. (2005) “Coming out at Work: Performativity and the Recognition and Renegotiation of Identity", The Sociological Review, 53 (3): 447-475.

Ward, J., Winstanley, D. (2007) "Sexuality and the City: Exploring the Experience of Minority Sexual Identity through Storytelling", Culture and Organization, 10 (3): 219-236. 